\title{
Efficacy of antidepressants in juvenile depression: meta-analysis
}

\author{
Evangelia M. Tsapakis, * Federico Soldani, ${ }^{\star}$ Leonardo Tondo and Ross J. Baldessarini
}

\section{Background}

The safety of antidepressants in children and adolescents is being questioned and the efficacy of these drugs in juvenile depression remains uncertain.

\section{Aims \\ To assess antidepressant efficacy in juvenile depression.}

\section{Method}

Systematic review and meta-analysis of randomised controlled trials (RCTs) comparing responses to antidepressants, overall and by type, $v$. placebo in young people with depression.

\section{Results}

Thirty drug-placebo contrasts in RCTs lasting 8 weeks (median) involved 3069 participants (512 person-years) of average age 13.5 years. Meta-analysis yielded a modest pooled drug/placebo response rate ratio $(R R=1.22,95 \% \mathrm{C}$ 1.15-1.31), with little separation between antidepressant types. Findings were similar for response rate differences and corresponding number needed to treat (NNT): overall NNT=9; tricyclic antidepressants NNT=14 > serotonin reuptake inhibitors NNT=9 $>$ other antidepressants NNT=8. Numbers needed to treat decreased with increasing age: children $(N N T=21)>$ mixed ages $(N N T=10)>$ adolescents (NNT=8).

\section{Conclusions}

Antidepressants of all types showed limited efficacy in juvenile depression, but fluoxetine might be more effective, especially in adolescents. Studies in children and in severely depressed, hospitalised or suicidal juvenile patients are needed, and effective, safe and readily accessible treatments for juvenile depression are urgently required.

\section{Declaration of interest}

E.M.T. has received research support from Johnson \& Johnson Psychiatry Research and Development. L.T. has received research support or served as a consultant to JDS, IFI, Eli Lilly and Janssen Pharmaceutical Corporations. R.J.B. is a consultant to or has received research support from Janssen, IFI, JDS, Eli Lilly, Novartis and Solvay Pharmaceutical Corporations. Funding is detailed in the Acknowledgements.
Unprecedented attention is being directed towards the treatment of children with serotonin reuptake inhibitors (SRIs) and other antidepressants, owing to concerns about potential increases in the risk of suicidal thoughts and perhaps suicide attempts, arising from randomised controlled trials of these drugs $v$. placebo. ${ }^{1-13}$ These concerns may be having an effect of reducing usage of SRIs as well as limiting new diagnoses of adult as well as juvenile depression. ${ }^{14-16}$ Given the importance of rationally balancing the risks and benefits of antidepressant treatment of children and adolescents, we carried out a systematic meta-analysis aimed at critically evaluating the magnitude of efficacy of all types of antidepressants. We also compared treatment responses in children $v$. adolescents and with SRIs $v$. other types of antidepressants, and identified factors associated with measures of treatment efficacy.

\section{Method}

\section{Search strategy and criteria}

We searched computerised databases for published or unpublished trials in which any antidepressant was compared with placebo among participants aged 20 years or less and diagnosed with major depressive disorder. Sources included MEDLINE, PsycInfo, the Cochrane Central Register of Controlled Trials, PsiTri, EMBASE and ClinicalTrials.gov, each through May 2006, without language restrictions. In a further effort to locate studies, we examined reference lists of identified publications and reviews; consulted pharmaceutical company websites for unpublished trial results and contacted authors of identified reports to clarify

*These authors contributed equally to the work. methodological questions and to seek unpublished data that could be included; consulted experts in paediatric psychiatry and psychopharmacology in both the EU and USA; and searched the UK Committee on Safety of Medicines and the US Food and Drug Administration websites for relevant information.

The first author (E.M.T.) initially screened reports for potential usefulness, identifying placebo-controlled trials involving juvenile patients diagnosed with a depressive illness and treated with antidepressants. The first and second authors (E.M.T., F.S.) then applied the following inclusion criteria independently, and reached consensus with the other authors. The criteria were:

(a) prospective, parallel groups, double-blind trial design with random assignment to an antidepressant or placebo;

(b) meeting standard diagnostic criteria of DSM-III (or later) ${ }^{17}$ for a depressive disorder (major depression, dysthymia or depression not otherwise specified) or of ICD-9/10 ${ }^{18}$ for depressive disorder, or diagnosis by clinical or structured diagnostic interview;

(c) participants aged 20 years or less;

(d) 'responder' rates reported as participant counts in each treatment arm (responders/participants exposed to drug or placebo, $n / N)$ and not only as average percentage change in symptom rating scale scores.

Ultimately 29 of 304 initially screened studies met these criteria; ${ }^{5,19-44}$ Fig. 1 shows a summary of the study selection process as recommended by the Quality of Reporting of Meta-analyses (QUOROM) statement. ${ }^{45}$ All 29 studies had antidepressant and placebo arms, and one included a third arm (placebo $v$. SRI $v$. tricyclic antidepressant), ${ }^{38}$ to yield 30 drug-placebo contrasts for meta-analysis. 


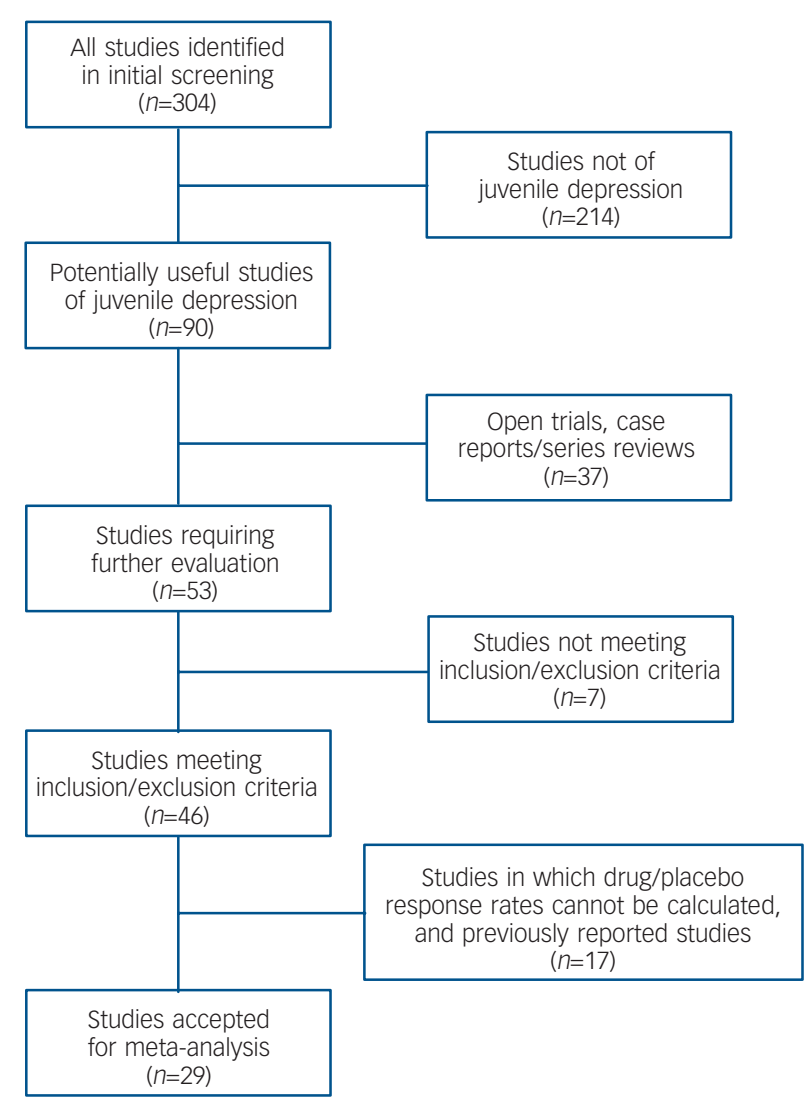

Fig. 1 Selection process for studies to be included in the meta-analyses reported.

\section{Data extraction}

First author E.M.T. extracted data from reports, which were verified independently by F.S.; discrepancies were resolved by consensus of all authors. For studies reported more than once, we used the most complete samples available. Information extracted included items required for meta-analysis of efficacy rate ratios and for meta-regressions outlined below. For continuous measures of clinical symptom rating scales we compiled a uniform percentage scale of clinical severity (maximum possible scale score set at 100\%): for example, for the 21-item Hamilton Rating Scale for Depression the maximum score of 68 points was taken as $100 \%$, so that entry scores of 20 or more were considered equivalent to percentage scores of $29.4 \%$ or over; other scale conversions are defined below. Definitions of 'treatment responder' varied between studies. Adherence to randomly assigned study medication and precise days of treatment exposures were reported inconsistently, but the percentage of patients retained was available for all studies.

We compared doses across agents and studies by use of standardised imipramine equivalent (IMIeq) daily doses, despite the lack of firm definitions of clinical dose-effect relationships with tricyclic antidepressants or SRIs at any age. The potency ratios selected were based on the empirical option of estimating median doses from manufacturers' recommendations, textbook summaries, and clinical practice with actually employed doses for each agent, derived largely from studies and clinical experience with adults. ${ }^{46}$

\section{Meta-analysis}

'Responder' rate (proportion of sample attaining a studyspecified level of improvement in clinical ratings, typically at least
$50 \%$ of initial ratings of depressive symptom severity) was determined for the primary categorical outcome measure defined in each study (or that most consistent with other trials when a primary outcome was not specified) to distinguish responders $(n)$ and non-responders $(N-n)$. Statistical analyses employed Intercooled Stata software, version 9.2 for Windows (2006, StataCorp, College Station, Texas, USA). Trial results were combined through the Stata METAN command, using fixed-effects models to estimate pooled Cochran-Mantel-Haenszel drug:placebo rate ratios (RRs) and rate differences (RDs) and their 95\% confidence intervals for all antidepressants combined, for each drug type considered separately (tricyclic antidepressants 14 trials; SRIs 12 trials; other drugs - mirtazapine, moclobemide, nefazodone - 4 trials), and for reported age groups (adolescents 16 trials; mixed ages 10 trials; children 4 trials). Random-effects models were also considered, based on tests for interstudy heterogeneity in selecting the reported pooled values, as recommended by DerSimonian \& Laird. ${ }^{47} \mathrm{~A}$ forest plot (rate ratio for each trial and a pooled value, with $95 \%$ confidence intervals, and symbol size proportional to study size and variance) summarised salient results graphically (Fig. 2).

The reported models underwent influence analyses, based on recalculating estimates of pooled rate ratios or rate differences after excluding individual trials serially, to identify those with unusually high influence on pooled estimates. Additional sensitivity analyses assessed effects of double inclusion of participants receiving placebo from a three-arm study. ${ }^{38}$ We used $Q$ and $I^{2}$ statistics to test for heterogeneity, and computed pooled estimates by both Cochran-Mantel-Haenszel and inverse variance methods. We assessed potential publication bias with Begg's ${ }^{48}$ and Egger's ${ }^{49}$ tests, funnel plots (of the standard error of each trial rate ratio estimate $v$. each rate ratio, to test for symmetry of distribution of values above and below the computed pooled rate ratio at all observed levels of s.e.) and meta-regression analyses. We also reported the weighted number needed to treat (NNT) (or to harm, NNH) to obtain an antidepressant response from one additional patient, as estimated by the reciprocal of the fixed-effects rate differences and their $95 \%$ confidence intervals. ${ }^{50}$

\section{Meta-regression}

To evaluate study or participant characteristics associated with trial outcomes, we conducted meta-regression analyses of rate ratios $v$. the following study characteristics: drug type (tricyclic antidepressants $v$. SRIs $v$. other antidepressants); sample size; publication year; published $v$. unpublished; type of analysis - completer $v$. last observation carried forward (LOCF); funding source (industry-sponsored or not); exposure weeks; and estimated methodological quality of each study based on Jadad ratings (from 1 to a high score of 4$).{ }^{51}$ Additional patient characteristics considered were age group (children, mixed ages, adolescents); average drug dose (approximate equivalent to imipramine in $\mathrm{mg} /$ day, based on a typical daily dose of $150 \mathrm{mg}$ /day for imipramine) ${ }^{46}$ in-patient/out-patient status; and baseline illness severity (percentage of maximum scale score required for trial entry). Variables were considered further based on their ability to alter the estimated pooled rate ratio by 0.10 or more. Based on preliminary univariate regressions to support ranking their effects on rate ratio, we then introduced variables into a meta-regression model in descending rank order.

\section{Results}

\section{Search findings}

The search strategy yielded 304 non-duplicative citations, from which 90 pertained to treating juvenile depression (Fig. 1). Of 


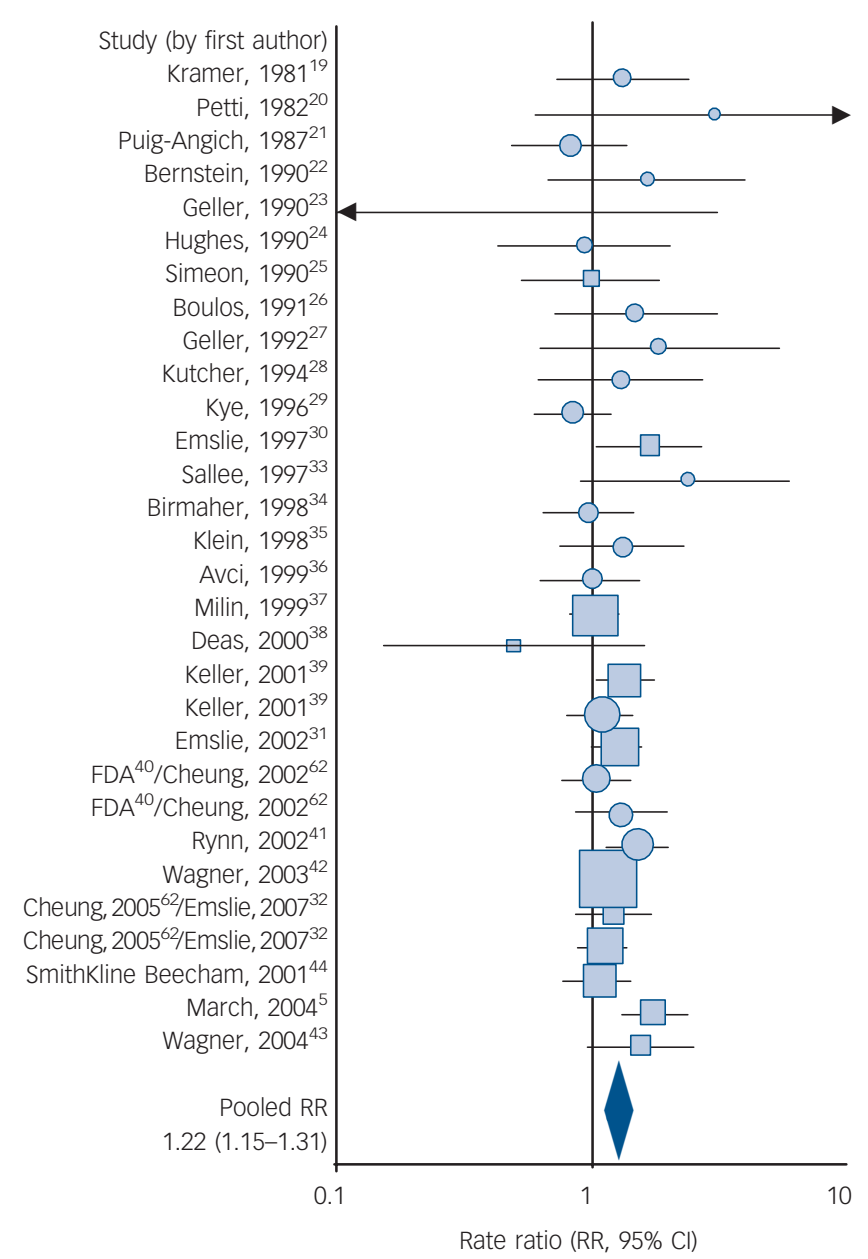

Fig. 2 Forest plot of rate ratios (RR, with $95 \% \mathrm{Cl}$ ) of responses to drug or placebo in 30 randomised double-blind placebocontrolled comparisons of rates of 'response' to antidepressants v. placebo, with overall pooled RR $(1.22 ; 95 \% \mathrm{Cl} 1.15-1.31$; blue diamond), based on meta-analysis

Squares represent trials of serotonin reuptake inhibitors (SRIs; 12 trials); circles represent tricyclic antidepressants (TCAs; 4 trials) and other types of antidepressants ( 4 trials); the size of the data point is proportional to weight defined by study participant number and measurement variance.

these, 37 were open trials, anecdotal case series or reviews, and 7 of the remaining 53 did not meet full inclusion criteria. In 17 of the 46 trials remaining, specific responder rates $(n / N)$ were not provided or data were reported in preliminary versions of included studies, leaving 29 trials (with 33 treatment arms). We also excluded the alprazolam arm of one study, ${ }^{22}$ and two arms involving unmasked psychotherapy with or without fluoxetine in another. $^{5}$ Of the remaining 29 studies, 5 were reported as abstracts or summaries from meetings, the US Food and Drugs Administration website or corporate websites..$^{35,37,39,41}$ One report included data from two trials of the atypical antidepressant mirtazapine, ${ }^{39}$ and another contained results from two trials of the SRI-like agent venlafaxine. ${ }^{44}$ In summary, there were 30 contrasts arising from 29 randomised controlled trials for meta-analysis.

\section{Characteristics and quality assessment of included studies}

A total of 3069 participants were represented, not counting 91 placebo-treated participants in the study by Keller et $a l^{38}$ considered twice in placebo comparisons with an SRI or tricyclic antidepressant (online Table DS1). The weighted mean participant age was 13.5 years (s.d. $=0.4$, median $=14.5$, range $6-20$ ). Most trials with both children and adolescents did not report response rates for each age group separately. Only 4 studies (all involving tricyclic antidepressants) separately considered 121 (3.9\%) children aged 12 years or less, ${ }^{20,21,24,27}$ so that randomised controlled trials of modern antidepressants involving only or separately reported children with depression were not available. Adolescent participants $(n=1427)$ were considered separately in the majority of comparisons (16 of 30 trials, 53\%), representing $46.5 \%$ of all participants. Ten other samples $(33 \%)$ included both adolescents and children $(n=1521)$, representing $49.6 \%$ of participants. Information about gender-specific treatment effects was not provided in most reports.

Of 30 drug-placebo comparisons considered (Table DS1), 14 involved tricyclic antidepressants, including amitriptyline, clomipramine, desipramine, imipramine and nortriptyline; 12 involved SRI-type agents, including R,S-citalopram, fluoxetine, paroxetine, sertraline and venlafaxine; 4 involved other antidepressants, including the reversible type A monoamine oxidase inhibitor (MAOI-A) moclobemide and atypical agents mirtazapine and nefazodone. One trial involved three arms, with paroxetine or imipramine $v$. placebo, ${ }^{38}$ and another included adolescents with depression and comorbid alcohol misuse. ${ }^{36}$

In addition to being randomised, double-blind and placebocontrolled, all trials included use of modern standardised diagnostic criteria (Research Diagnostic Criteria for major depressive disorder, $^{52}$ DSM-III or later, or ICD-9/10) to diagnose clinical depression - major depressive disorder in $89.7 \%$ of cases. All studies except the earliest SRI trial ${ }^{25}$ were considered adequate with respect to randomisation and masking. Quality ratings averaged 2.97 (s.d. $=0.76$, median=3.0, range $1-4),{ }^{51}$ and proportions of trials with high-quality scores ( 3 or 4 ) ranked tricyclic antidepressants $(12 / 14$ trials, $86 \%)>$ other antidepressants $(3 / 4$ trials, $75 \%)$ $>$ SRIs (8/12 trials, 67\%; online Tables DS1 and DS2). Outcomes were given for participants who completed the trials in only 6 studies; , $2,26,30,35,37,38$ the other 23 involved LOCF-based outcomes (Table DS1). Given the scarcity of 'completer' analyses and the possible superiority of LOCF analysis, in order to enhance consistency and maximise the sample available for analysis, the reported results are based on LOCF outcomes.

\section{Drug doses and exposure times}

All studies included provided drug doses consistent with contemporary paediatric practice, based on body-weight-adjusted daily dosing $(\mathrm{mg} / \mathrm{kg})$ considered standard for treating adult major depressive disorder. ${ }^{46}$ The overall IMIeq drug dose averaged $165 \mathrm{mg} /$ day (s.d.=48). Median doses (25th-75th percentile values) for the three major drug classes ranked tricyclic antidepressants 200 (140-220) mg/day > other antidepressants 178 (156-180) $\mathrm{mg} /$ day $>$ SRIs $132(106-161) \mathrm{mg} /$ day (Table DS2). By age groups, median (25th-75th percentile) doses ranked adolescents $200(139-212) \mathrm{mg} /$ day $>$ mixed ages $160(102-168) \mathrm{mg} /$ day $>$ children $140(100-144) \mathrm{mg} /$ day, suggesting similar $\mathrm{mg} / \mathrm{kg}$ daily dosing.

Reported nominal trial durations yielded a weighted (by N/ study) average exposure time of 8.7 weeks (median $=8$, range 112), indicating an overall trial experience of approximately 512 person-years. Withdrawal rates and actual exposure times are not described for most trials, but drug treatment averaging approximately 8 weeks should be adequate to detect antidepressant effects, at least based on studies in adult depression. ${ }^{46}$ The studies analysed included three relatively brief trials - a 5-week trial of a 
tricyclic antidepressant, ${ }^{21}$ another of a short-acting MAOI,${ }^{34}$ and a 1-week trial of a tricyclic antidepressant. ${ }^{31}$ Total exposures (median) differed substantially between drug types, ranking SRIs 1584 person-weeks $>$ other antidepressants 1000 person-weeks $>$ tricyclic antidepressants 248 person-weeks (Table DS2). This imbalance of both exposure times and participant counts indicates major mismatching, tending to favour SRIs over tricyclic antidepressants, whereas median estimated IMIeq daily doses of SRIs were $34 \%$ lower than those of tricyclic antidepressants (Table DS2). Among age groups, median exposures ranked: adolescents and children 1148 person-weeks $>$ children 281 person-weeks $>$ adolescents 262 person-weeks. When both dose (IMIeq mg/ day) and average exposure time (weeks) are considered together, there is no overall difference between drug types: SRIs mean $=1232$ mg-weeks (s.d.=269); tricyclic antidepressants mean=1239 mgweeks (s.d. $=642$ ); other antidepressants mean=1257 mg-weeks (s.d.=339); one-way analysis of variance (ANOVA), $F=0.004$, d.f. $=2,27, P=0.996$.

\section{Initial depression severity}

We used a uniform percentage scale to represent initial illness severity across rating methods. Maximum scores on the 21-item Hamilton Rating Scale for Depression (HRSD; maximum score 68), the 17-item HRSD (maximum score 55), the MontgomeryÅsberg Depression Rating Scale (maximum score 60), the Psychiatric Rating Scale (maximum score 16), the School-Aged Depression List Interview (maximum score 119), the Children's Depression Rating Scale (maximum score 63), the Children's Depression Rating Scale - Revised (maximum score 113) and the Children Depression Inventory (maximum score 100) were all rated as $100 \%$. Based on such normalised scaling, initial illness severity ratings were similar across placebo (mean $=46.4$, s.d. $=15.9$, median $=49.9)$ and antidepressant (mean $=47.5$, s.d. $=16.7$, median $=49.6$ ) arms, indicating moderate to severe intensity of baseline depressive symptoms in most trials, all of which involved young people receiving out-patient treatment for depression. These initial depression ratings for participants randomised to drugs or placebo did not differ appreciably across drug types (Table DS2).

\section{Treatment efficacy}

We defined primary outcomes for meta-analysis a priori as responder status, based on changes in clinical ratings from intake to last observation point (as defined in each trial) involving substantial improvement, typically a $50 \%$ or greater reduction in symptomatic ratings of depression on standardised scales (Table DS1). Data pertaining to other outcomes of potential interest, including changes in continuous measures of depression severity, rates of clinically significant improvements or syndromal remission, and withdrawal rates, were reported too inconsistently to support systematic analysis.

Preliminary consideration of median response rates indicated modest differences between antidepressants and placebo, averaging $10.9 \%$ overall $(60.1 \%$ with antidepressants $v .49 .2 \%$ with placebo), and ranging from a difference of $8.0 \%$ for SRIs to $12.3 \%$ for tricyclic antidepressants (Table DS2). These average contrasts also were similar between age groups, ranging from $8.0 \%$ in adolescents to $16.2 \%$ in children, with a plausible intermediate difference of $11.6 \%$ in mixed-age juveniles (one-way ANOVA: $F=0.304$, d.f. $=2,27, P=0.740$; not shown), suggesting greater drug response with brain maturation.

Comparative efficacy of treatment with an antidepressant $v$. placebo, based on responder rates (i.e. proportions), is shown for all 30 available contrasts, as response rate ratios and rate differences and their 95\% confidence intervals, based on metaanalysis (Fig. 2, Table DS3). Most trials (22/30 trials, 73\%) yielded rate ratios of 1.0 or above, but only $6(20 \%)$ met the criterion that the lower limit of the confidence interval of the trial rate ratio should be $>1.0$, and 5 of these involved an SRI - that is, fully $80 \%$ of comparisons (24/30) failed to meet this criterion of superiority of antidepressant over placebo, reflecting small effect differences.

An estimate of pooled overall effect size, based on metaanalysis to determine a pooled rate ratio and its confidence interval for all 30 trials, yielded a value of 1.22 (95\% CI 1.151.31 ), indicating moderate $(22 \%)$ overall superiority of antidepressant over placebo response rate on the multiplicative scale (Fig. 2, Table 1). Preliminary testing for interstudy variance $(Q)^{48}$ in this $(P=0.28)$ and other meta-analyses (Table 1) supported use of a fixed-effects meta-analysis model. However, random effects modelling yielded a similar overall pooled rate ratio of 1.20 (95\% CI 1.11-1.29).

Serotonin reuptake inhibitors yielded a higher response rate ratio $(\mathrm{RR}=1.23,95 \% \mathrm{CI} 1.14-1.33)$ than tricyclic antidepressants $(\mathrm{RR}=1.15,95 \%$ CI $0.98-1.34)$, but the overlapping confidence intervals indicate statistical non-separation by drug type. Of the SRIs, in its four trials (Table DS1) fluoxetine showed somewhat greater pooled efficacy than in eight trials of other SRIs: respectively, $\mathrm{RR}=1.45$, 95\% CI 1.24-1.70, range $1.00-1.74 v$. RR=1.16, 95\% CI 1.06-1.27, range $0.50-1.53$; rate difference $\mathrm{RD}=0.196$, $95 \% \quad$ CI $\quad 0.117-0.276 \quad v . \quad \mathrm{RD}=0.083, \quad 95 \%$ CI $0.034-0.131$; $\mathrm{NNT}=5.8,95 \%$ CI $4.0-10.8 v$. NNT $=12.2,95 \%$ CI $7.7-29.4$. The

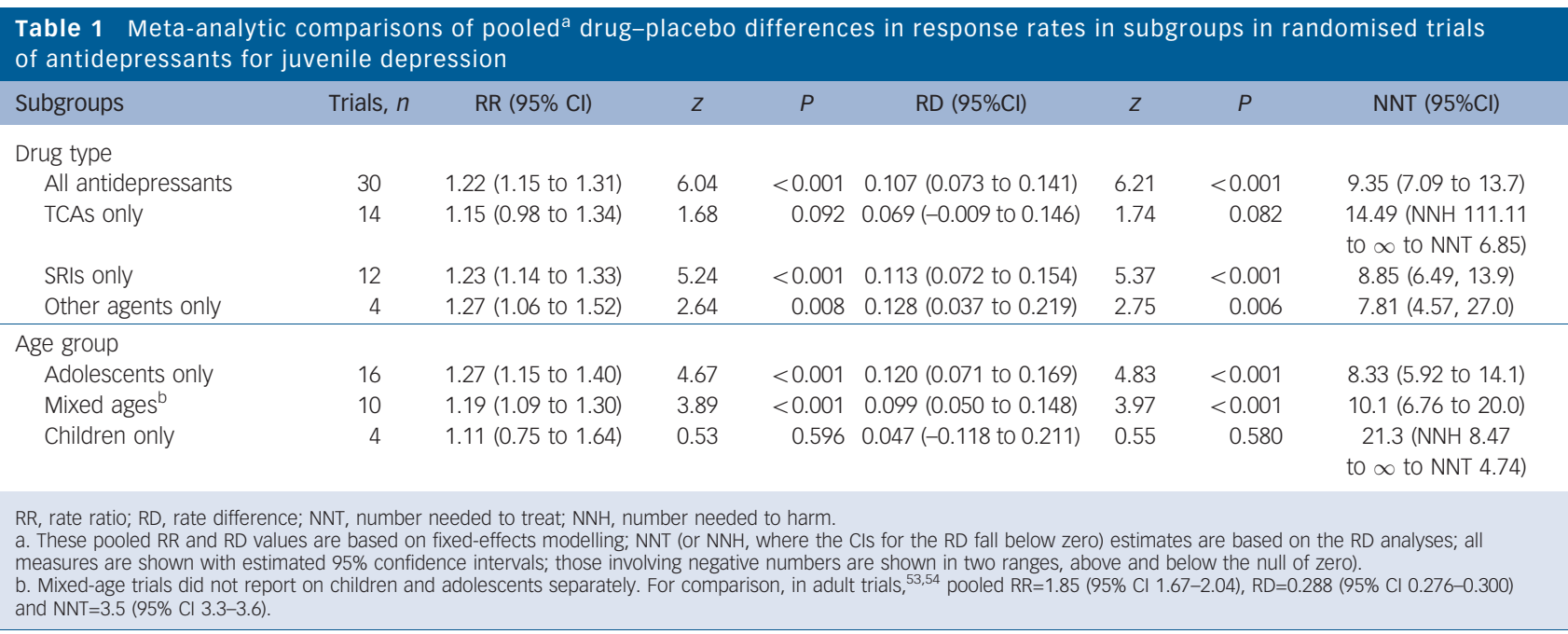


largest effect size for fluoxetine was reported by March et al $(\mathrm{RR}=1.74,95 \%$ CI $1.29-2.34),{ }^{5}$ whereas its three remaining trials (Simeon et $a l,{ }^{25} \mathrm{RR}=1.00$; Emslie et $a l,{ }^{30} \mathrm{RR}=1.68$; Emslie et $a l,{ }^{40}$ $\mathrm{RR}=1.27$; Table DS3) yielded pooled effects ( $\mathrm{RR}=1.32,95 \% \mathrm{CI}$ 1.10-1.59) similar to other antidepressants (overall $\mathrm{RR}=1.22$, 95\% CI 1.15-1.31). Other types of antidepressants tested in a small number of trials yielded a slightly higher pooled rate ratio $(\mathrm{RR}=1.27,95 \%$ CI 1.06-1.52) than did the SRIs (Table 1), and again the $95 \%$ confidence intervals overlapped, and the weighted NNT estimates confirmed such overlap of efficacy. For all 30 trials, the NNT was 9.35 (95\% CI 7.09-13.7); for tricyclic antidepressants the NNT was 14.49 (NNH 111.11 to $\infty$ to NNT 6.85, to manage the rate difference in the $95 \% \mathrm{CI}$ range falling below zero); for SRIs the NNT was 8.85 (95\% CI 6.49-13.9); and for other types of antidepressants it was 7.81 (95\% CI 4.57-27.0).

\section{Effects of age}

The three age groups yielded an interesting progression of rising pooled rate ratio values with increasing age: children $(\mathrm{RR}=1.11$, 95\% CI $0.75-1.64)<$ juveniles of mixed ages $(\mathrm{RR}=1.19,95 \%$ CI 1.09-1.30) < adolescents $(\mathrm{RR}=1.27,95 \%$ CI 1.15-1.40; Table 1 ), with similar increases in rate differences and corresponding decreases of NNT by age (about 21, 10 and 8 respectively). For comparison with results from randomised placebo-controlled trials of antidepressants in adults, we applied meta-analysis to findings from over 250 trials involving 23500 participants. ${ }^{54,55}$ For adults, the overall pooled, random-effects rate ratio was 1.85 (95\% CI $1.67-2.04 ; z=12.3, P<0.001)$ and the overall rate difference was 0.288 (95\% CI $0.276-0.300 ; z=46.2, P<0.001$ ), with an estimated NNT of 3.5 (95\% CI 3.3-3.6), and results were similar for the different types of antidepressants (not shown). These findings add to the impression that antidepressant efficacy may increase with age.

\section{Reporting bias and influence of individual trials}

A funnel plot (s.e. of RR $v$. RR) encompassing published and unpublished trials indicated somewhat asymmetrical distribution of individual trial rate ratios leaning towards the positive about the pooled value of 1.22 as a function of the variance (s.e.) of individual trial RRs ( $R R$ values $>1.22$ averaged 0.42 , s.e. $=0.47 v$. $<1.22$ averaged 0.27 , s.e. $=0.23$, a 1.54-fold difference) (not shown), and in meta-regression analyses the rate ratio was $22.0 \%$ (95\% CI 1.5-41.8) higher in published $v$. unpublished trials, although unadjusted Begg's $(P=0.34)$ and Egger's $(P=0.30)$ tests did not indicate publication bias. We could not determine whether additional trials failing to find superior effects of antidepressants over placebo exist as unreported findings. Nevertheless, the preceding observations suggest that publication might have been biased towards studies favouring drug over placebo, perhaps tending to inflate available efficacy estimates.

Based on sensitivity or influence analysis, excluding one trial at a time and recalculating pooled rate ratio estimates, we found only trivial effects on the pooled rate ratio, including omission of the shortest trial, ${ }^{31}$ which accordingly was included in the overall analyses. The US federal grant-supported Treatment for Adolescents with Depression study by March et $a l^{5}$ was identified as the most influential study, based on its unusually large effect size $(\mathrm{RR}=1.74,95 \%$ CI $1.29-2.34)$ and larger sample size $(n=221)$ than in any other trial (Table DS3). Excluding this single trial reduced the overall pooled rate ratio to 1.20 (95\% CI $1.12-$ 1.28) from the overall rate ratio of 1.22 .

\section{Meta-regression analyses}

Characteristics associated with a change in estimates of treatment effect (rate ratio) of at least 0.10 included outcome based on protocol completion $v$. LOCF methods; greater illness severity at entry; and published $v$. unpublished reports. Rate ratio estimates increased by approximately $10 \%(95 \% \mathrm{CI}-13.4$ to 31.8$)$ for each $20 \%$ increase in depression severity ratings at intake. The less common method of 'completer' analysis (only 6 of 29 trials) was associated with a nearly $20 \%(95 \% \mathrm{CI}-11.6$ to 51.3$)$ greater rate ratio than LOCF-based methods. Other factors considered (drug type, sample size, publication year, funding source, exposure weeks, estimated study methodological quality ratings, age group, average drug dose and in-patient or out-patient status) had only weak associations with drug/placebo response rate ratios. By adjusting the computed pooled response rate ratios for all three most influential covariates, the rate ratio difference between 'older' and 'newer' antidepressants persisted, but was even smaller (0.19) than without such adjustment (0.22). Specifically, these considerations fail to support the possibility that SRIs may be superior in efficacy to tricyclic antidepressants.

\section{Discussion}

The main findings in this meta-analytic review are that antidepressants have shown limited clinical efficacy in depression in adolescents, less among juvenile patients of mixed ages, and are poorly studied, but possibly even less effective, in children, and substantially less effective in juveniles than in adults. ${ }^{46,53-55}$ On average, in juvenile participants with depression, drug and placebo response rates differed by only $10 \%$ and the pooled risk ratio was modest at 1.22 (Tables DS1, DS2). Drug and placebo response rates also differed little between drug types, and potential gender differences were indeterminate. The $\mathrm{mg} / \mathrm{kg}$ body weight daily doses of antidepressants employed in the trials analysed were similar to those considered typical for adults with depression. ${ }^{46}$

In line with recent British advisory recommendations, ${ }^{56}$ this systematic review found limited efficacy for all types of antidepressants in short-term randomised controlled trials in juvenile depression. Earlier reviews of treatment of juvenile depression concluded that tricyclic antidepressants were ineffective, particularly in prepubertal children, with marginal efficacy in adolescents. ${ }^{57-59}$ Reviews of SRIs also have suggested limited antidepressant benefits in cases of juvenile depression. ${ }^{12,59-65}$ Seemingly consistent with selective UK and US regulatory approval of fluoxetine for juvenile depression, there is some evidence of its apparent superiority to other SRIs, although this impression rests heavily on one large study with an unusually large drug-placebo separation. ${ }^{5}$ Conceivably the unusually long duration of action of fluoxetine ${ }^{46}$ might be advantageous among treatment-reluctant and poorly treatment-adherent young patients. That antidepressants, and particularly SRIs, have mood-elevating effects in children and young adolescents is suggested by the substantial risk of these patients becoming excited or manic during treatment for apparent major depression. ${ }^{66}$ Moreover, the modest evidence of efficacy in randomised controlled trials is at variance with the widespread empirical acceptance of modern antidepressants in paediatric clinical practice. ${ }^{67-69}$

A striking finding in our analysis is the limited difference found between outcomes with SRIs $v$. tricyclic antidepressants: with raw median response rates actually tended to favour the latter drugs, and meta-analytically pooled rate ratios differed little (7.7\%), with highly overlapping confidence intervals, indicating statistical non-difference (Table DS2). Superiority of antidepressants over placebo in juvenile patients with major 
depressive disorder, based on statistical significance, was found in only $20 \%$ of 30 comparisons, including $0 / 14$ comparisons involving tricyclic antidepressants, $0 / 4$ involving other antidepressants, and only 5/12 comparisons involving SRIs (Table DS1). However, this way of comparing study results is confounded by the severe mismatching of participant numbers and treatment duration in trials of tricyclic antidepressants $v$. SRIs: notably, trials of SRIs had over six times greater treatment exposure in personweeks (Table DS2). Greater statistical power gained with higher participant counts can yield 'significant' separation of drug from placebo, even though such separation may be small and of questionable clinical significance. Recent trials have been much larger (and longer) and so more likely to yield statistical separation of SRIs $v$. placebo, but without either a clinically or statistically meaningfully larger pooled effect size (rate ratio or rate difference) or smaller NNT in association with larger participant counts, as noted above. This mismatching of statistical power and exposure time (favouring SRIs) is to be contrasted with a $34 \%$ lower estimated equivalent daily dosing with SRIs than tricyclic antidepressants (Table DS2), which had a negligible effect on metaregression outcomes. Nevertheless, in depressed patients of any age at high risk of suicidality, routine use of tricyclic antidepressants cannot be recommended in view of their known cardiotoxic effects and associated mortality in overdose.

Proposed explanations for such disappointing findings in the experimental therapeutics of juvenile depression include both methodological aspects of trial design and clinical aspects of juvenile mood disorders. Possibilities include relatively high rates of response to placebo or other non-specific interventions; ageinappropriate or insufficiently sensitive outcome measures; inadequately powered trials; adverse case selection (e.g. minimally ill, uncertain or heterogeneous diagnoses, previous treatment failures, poorly cooperative participants); incomplete control of substance misuse; inadequate dosing or duration of treatment; and simple lack of efficacy in juvenile $v$. adult mood disorders. ${ }^{60,63,70-73}$ The average $60 \%$ drug response rate in juvenile depressed patients (Tables DS1, DS2) was similar to that reported in depressed adults, ${ }^{46,53,55}$ suggesting that neither the major developmental changes in drug disposition ${ }^{74,75}$ nor possible changes in pharmacodynamics are involved in the limited superiority of antidepressants to placebo in juvenile depression.

Poor separation in responses to antidepressants $v$. placebo may reflect recruitment of juveniles with relatively heterogeneous illnesses, who may meet nominal diagnostic criteria for major depressive disorder, but whose symptoms may not be representative of classic disorders, such as the clearly endogenous and melancholic features associated with adult major depression. Juvenile major depressive disorder was not accepted into the official American diagnostic nomenclature until the late 1990s. ${ }^{17,76,77}$ Differentiation of mood disorders from other prevalent behavioural and emotional conditions in young patients remains descriptive. Improved diagnostic and clinical rating methods may increase reliability of the diagnosis of major depressive disorder in children and adolescents, although not necessarily assure valid comparison with major depressive syndromes of adults. $^{70,71,78}$ Even though median baseline depression severity scores were at the mid-range of scale scores (averaging 50\%; Table DS2), suggesting substantial illness severity, sampling of young patients with depression may include a high proportion of relatively mildly ill patients, who have most probably never received in-patient treatment, and who are more likely to improve spontaneously with or without additional effects of placebo treatment. $^{79}$

Importantly, prepubertal children with depression may differ biologically from adolescents or adults, ${ }^{66,74,80}$ and it remains unclear whether depression in prepubertal children is a substantially different disorder from that found in adolescents or adults, perhaps including developmental differences in either the pharmacodynamics of antidepressants or in their clinical effects. ${ }^{66,81}$ The current data preclude adequate assessment of potential developmental effects owing to the paucity of studies of children considered separately. Only 4 of 30 treatment comparisons and $4 \%$ of participants involved children only; all were treated with tricyclic antidepressants, none with modern drugs. Nevertheless, within the limits imposed by the few studies of children, no major systematic difference was apparent between depressed children and adolescents in average rates of clinical improvement during treatment with either antidepressants or placebo, nor in pooled rate ratios (Table 1).

\section{Implications}

The limited benefits of antidepressant treatment for depression in children and adolescents found in reported results of randomised controlled trials have important risk-benefit implications, given current discussion of risks that may include more suicidal thinking and perhaps self-injurious behaviour in juvenile patients with depressive or anxiety disorders during treatment with an SRI. Clearly, additional research is required to clarify the basis of the limited juvenile responses to antidepressant treatments considered standard in adult major depression, to specify developmental changes in antidepressant potency and pharmacodynamics as well as potential age-related differences in treatment responses and risks involved. Moreover, questions of risks $v$. benefits of antidepressant treatment of juvenile depression require critical assessments of the relative value of modest effect sizes, typically based on $50 \%$ reductions in symptom ratings as reviewed here, $v$. actual clinical effectiveness (efficacy plus acceptability sufficient to yield clinical recovery), which remains to be studied in children and adolescents. Outcomes in future trials might be enhanced by including larger samples, more severely depressed participants, more children and narrower age groups. Trials should also include information on the proportion of individuals with mild or moderate depression at baseline. Moreover, results of all well-designed trials should be made publicly available regardless of outcome, since publication bias may affect available meta-analytical estimates of efficacy or adverse effects on which clinical therapeutic practices and public health policies are based. Urgent goals should include development of more effective, safe, cost-effective and accessible short-term and long-term treatments for juvenile depression, with specific consideration of differences between prepubertal children and adolescents.

\footnotetext{
Evangelia M. Tsapakis, BSC, MBBS, MSC, MRCPsych, Section of Clinical Neuropharmacology and MRC Social, Genetic and Developmental Psychiatry Centre, Institute of Psychiatry, King's College London, London, UK, and Department of Psychiatry, Harvard Medical School and Psychopharmacology Program, McLean Division of Massachusetts General Hospital, Boston, Massachusetts, USA; Federico Division of Massachusetts General Hospital, Boston, Massachusetts, USA; Federico
Soldani, MD, SM, PhD, Department of Epidemiology, Harvard School of Public Health and Department of Psychiatry, Harvard Medical School and Psychopharmacology Program, McLean Division of Massachusetts General Hospital, Boston, Massachusetts, USA; Leonardo Tondo, MD, SM, Lucio Bini Mood Disorder Centre and Department of Psychology, University of Cagliari, Sardinia, Italy, and Department of Psychiatry, Harvard Medical School and Psychopharmacology Program, McLean Division of Massachusetts General Hospital, Boston, Massachusetts, USA; Ross J. Baldessarini MDsachusetts General Hospital, Boston, Massachusetts, USA; Ross J. Baldessartment of Psychiatry, Harvard Medical School, Psychopharmacology Program and International Consortium for Bipolar Disorder Research, McLean Division of Massachusetts General Hospital, Boston, Massachusetts, USA

Correspondence: Dr Evangelia M. Tsapakis, MRC Social Genetic and Developmental Psychiatry Centre, Institute of Psychiatry, PO Box 80, De Crespigny Park, London SE5 8AF, UK. Email: e.tsapakis@iop.kcl.ac.uk

First received 15 Sep 2006, final revision 19 May 2007, accepted 11 Jul 2007
} 


\section{Acknowledgements}

The authors thank the Royal College of Psychiatrists, for awarding an Eli Lilly Travelling Fellowship to E.M.T.; the PhD programme in Psychiatry of the University of Pisa, the Harvard School of Public Health doctoral programme in Epidemiology and the IDEA Foundation, Milan for supporting F.S. and the Bruce J. Anderson Foundation and the McLean Private Donors Psychopharmacology Research Fund for research grants to R.J.B.

\section{References}

1 Committee on Safety of Medicines. Selective Serotonin Reuptake Inhibitor Antidepressants (http://www.mhra.gov.uk/Safetyinformation/ Safetywarningsalertsandrecalls/Safetywarningsandmessagesformedicines/ cON1004259?ssSourceNodeld=242\&ssTargetNodeld=221) (accessed 16 Dec 2007)

2 Jureidini JN, Doecke CJ, Mansfield PR, Haby MM, Menkes DB, Tonkin AL. Efficacy and safety of antidepressants for children and adolescents. BMJ 2004; 328: 879-83

3 Hammad TA, Laughren T, Racoosin J. Suicidality in pediatric patients treated with antidepressant drugs. Arch Gen Psychiatry 2006; 63: 332-3.

4 Newman TB. A black-box warning for antidepressants in children? N Engl J Med 2004; 351: 1595-8.

5 March JS, Silva S, Petrycki S, Curry J, Wells K, Fairbanks J, Burns B, Domino M, McNulty S. Fluoxetine, cognitive-behavioral therapy, and their combination for adolescents with depression. Treatment for Adolescents with Depression Study (TADS) randomized controlled trial. JAMA 2004; 292 807-20.

6 Baldessarini RJ, Pompili M, Tondo L, Tsapakis EM, Soldani F, Faedda GL, Hennen J. Antidepressants and suicidal behaviour: are we hurting or helping? Clin Neuropsychiatry 2005; 2: 73-5.

7 Baldessarini RJ, Pompili M, Tondo L. Suicidal risk in antidepressant trials: Commentary. Arch Gen Psychiatry 2006; 63: 332-9.

8 Mann JJ, Emslie G, Baldessarini RJ, Beardslee W, Fawcett JA, Goodwin FK, Leon AC, Meltzer HY, Ryan ND, Shaffer D, Wagner KD. ACNP Task force report on SSRIs and suicidal behavior in youth. Neuropsychopharmacol 2006 31: 473-92.

9 Hammad TA, Laughren T, Racoosin L. Suicidality in paediatric patients treated with antidepressants. Arch Gen Psychiatry 2006, 63: 332-9.

10 Food and Drug Administration: Laughren TP. Overview for a Meeting of the Psychopharmacology Drug Advisory Committee (PDAC) Concerning Suicidal Risk in Trials of Antidepressant Drugs in Juvenile and Adult Patients (http:// www.fda.gov/ohrms/dockets/ac/06/briefing/2006-4272b1-index.htm) (accessed 16 Dec 2007).

11 Olfson M, Marcus SC, Shaffer D. Antidepressant drug therapy and suicide in severely depressed children and adults. Arch Gen Psychiatry 2006; 63: 865-72.

12 Bridge JA, Iyengar S, Salary CB, Barbe RP, Birmaher B, Pincus HA, Ren L, Brent DA. Clinical response and risk for reported suicidal ideation and suicide attempts in pediatric antidepressant treatment. JAMA 2007; 287: 1683-96.

13 Friedman RA, Leon AC. Expanding the black box: depression, antidepressants, and the risk of suicide. N Engl J Med 2007; 356: 2343-6.

14 Libby A, Brent D, Morrato E, Orton HD, Allen R, Valuck RJ. Decline in treatment of pediatric depression after FDA advisory on risk of suicidality with SSRIS. Am J Psychiatry 2007; 164: 884-91.

15 Morrato EH, Libby AM, Orton HD, Degruy FV, Brent DA, Allen R, Valuck RJ. Frequency of provider contact after FDA advisory on risk of pediatric suicidality with SSRIS. Am J Psychiatry 2008; 165: 42-50.

16 Valuck RJ, Libby AM, Orton HD, Morrato EH, Allen R, Baldessarini RJ. Spillover effects on treatment of adult depression in primary care after FDA advisory on risk of pediatric suicidality with SSRIS. Am J PSychiatry 2007; 164: 1198-205.

17 American Psychiatric Association. Diagnostic and Statistical Manual of Mental Disorders (3rd edn) (DSM-III); 3rd revised edn (DSM-III-R); 4th edn (DSM-IV); 4th edn text revision (DSM-IV-TR). APA Press, 1980, 1987, 1994, 2000.

18 World Health Organization. International Classification of Diseases (ICD): Classification of Mental and Behavioural Disorders, Clinical Descriptions and Diagnostic Guidelines, ninth edition (ICD-9) and tenth edition (ICD-10). WHO, 1977, 1992.

19 Kramer AD, Feiguine RJ. Clinical effects of amitriptyline in adolescent depression. J Am Acad Child Adolesc Psychiatry 1981; 20: 636-44.

20 Petti TA, Law W. Imipramine treatment of depressed children: double-blind pilot study. J Clin Psychopharmacol 1982; 2: 107-10.

21 Puig-Antich J, Perel JM, Lupatkin W, Chambers WJ, Tabrizi MA, King J, Goetz $\mathrm{R}$, Davies M, Stiller RL. Imipramine in prepubertal major depressive disorders. Arch Gen Psychiatry 1987; 44: 81-9.
22 Bernstein GA, Garfinkel BD, Borchardt CM. Comparative studies of pharmacotherapy for school refusal. J Am Acad Child Adolesc Psychiatry 1990; 5: 773-81.

23 Geller B, Cooper TB, Graham DL, Marsteller FA, Bryant DM. Double-blind placebo-controlled study of nortriptyline in depressed adolescents using a fixed plasma level design. Psychopharmacol Bull 1990; 26: 85-90.

24 Hughes CW, Preskorn SH, Wrona M, Hassanein R, Tucker S. Follow-up of adolescents initially treated for prepubertal-onset major depressive disorder with imipramine. Psychopharmacol Bull 1990; 26: 244-8.

25 Simeon JG, Dinicola VF, Ferguson HB, Copping W. Adolescent depression: placebo controlled fluoxetine treatment study and follow-up. Prog Neuropsychopharmacol Biol Psychiatry 1990; 14: 791-5.

26 Boulos C, Kutcher S, Marton P, Simeon J, Ferguson B, Roberts N. Response to desipramine in adolescent major depression. Psychopharmacol Bull 1991; 27: 59-65.

27 Geller B, Cooper TB, Graham DL, Fetner HH, Marsteller FA, Wells JM. Pharmacokinetically designed double-blind placebo-controlled study of nortriptyline in 6- to 12-year-olds with major depressive disorder. J Am Acad Child Adolesc Psychiatry 1992; 31: 34-44.

28 Kutcher S, Boulos C, Ward B, Marton P, Simeon J, Ferguson HB, Szalai J, Katic $\mathrm{M}$, Roberts N, Dubois C, Reed K. Response to desipramine treatment in adolescent depression: a fixed-dose, placebo-controlled trial. J Am Acad Child Adolesc Psychiatry 1994; 33: 686-94.

29 Kye $\mathrm{CH}$, Waterman GS, Ryan ND, Birmaher B, Williamson DE, lyengar S, Dachille $\mathrm{S}$. A randomized, controlled trial of amitriptyline in the acute treatment of adolescent major depression. J Am Acad Child Adolesc Psychiatry 1996; 35: 1139-44.

30 Emslie GJ, Rush AJ, Weinberg WA, Kowatch RA, Hughes CW, Carmody T, Rintelmann J. A double-blind, randomized, placebo-controlled trial of fluoxetine in children and adolescents with depression. Arch Gen Psychiatry 1997; 54: 1031-7

31 Emslie GJ, Heiligenstein JH, Wagner KD, Hoog SL, Ernest DE, Brown E, Nilsson M, Jacobson JG. Fluoxetine for acute treatment in depression in children and adolescents: a placebo-controlled, randomized clinical trial. J Am Acad Child Adolesc Psychiatry 2002; 41: 1205-15.

32 Emslie GJ, Findling RL, Yeung PP, Kunz NR, Li Y. Venlafaxine ER for the treatment of pediatric subjects with depression: Results of two placebocontrolled trials. J Am Acad Child Adolesc Psychiatry 2007; 46: 479-88.

33 Sallée FR, Vrindavanam NS, Deas-Nesmith D, Carson SW, Sethuraman G. Pulse intravenous clomipramine for depressed adolescents: double-blind, controlled trial. Am J Psychiatry 1997; 154: 668-73.

34 Birmaher B, Waterman GS, Ryan ND, Perel J, McNabb J, Balach L, Beaudry MB, Nasr FN, Karambelkar J, Elterich G, Quintana H, Williamson DE, Rao U. Randomized controlled trial of amitriptyline vs. placebo for adolescents with 'treatment-resistant' major depression. J Am Acad Child Adolesc Psychiatry 1998; 37: 527-35.

35 Klein RG, Mannuzza S, Koplewicz HS, Tancer NK, Shah M, Liang V, Davies M. Adolescent depression: controlled desipramine treatment and atypical features. Depress Anxiety 1998; 7: 15-31.

36 Avci A, Diler RS, Kibar M, Toros F. Comparison of moclobemide and placebo in young adolescents with major depressive disorder. Ann Med Sciences 1999; 8: 31-40

37 Milin, R., Simeon, J., Spenst, W. Double-blind study of paroxetine in adolescents with unipolar major depression (GSK trial 29060/377). In Proceedings of the Forty-sixth Annual Meeting of the American Academy of Child and Adolescent Psychiatry, 1999 October 19-24, Chicago, Illinois, USA (http://www.gsk.com/media/paroxetine/depression_377_full.pdf) (accessed 16 Dec 2007).

38 Deas D, Randall CL, Roberts JS, Anton RF. A double-blind, placebo-controlled trial of sertraline in depressed adolescent alcoholics: a pilot study. Hum Psychopharmacol 2000; 15: 461-9.

39 Keller MB, Ryan ND, Strober M, Klein RG, Kutcher SP, Birmaher B, Hagino OR, Koplewicz H, Carlson GA, Clarke GN, Emslie GJ, Feinberg D, Geller B, Kusumakar V, Papatheodorou G, Sack WH, Sweeney M, Wagner KD, Weller EB, Winters NC, Oakes R, McCafferty JP. Efficacy of paroxetine in the treatment of adolescent major depression: a randomized controlled trial. J Am Acad Child Adolesc Psychiatry 2001; 40: 762-72.

40 Food and Drug Administration. Pediatric Supplement SE5-011 Executive Summary. FDA, 2001 (http://www.fda.gov/cder/foi/esum/2004/ 20415SE5_011_ Mirtazapine\%20MO\%20ReviewFIN.pdf) (accessed 16 Dec 2007).

41 Rynn MA, Findling RL, Emslie GJ, Marcus RN, Fernandes LA, D'Amico MF, Hardy SA. Efficacy and safety of nefazodone in adolescent with MDD (Abstract NR57). In Proceedings of the 155th Annual Meeting of the American Psychiatric Association (in Philadelphia, PA, May 18-23): New Research. American Psychiatric Press. 2002. 
42 Wagner KD, Ambrosini P, Rynn M, Wohlberg C, Yang R, Greenbaum MS, Childress A, Donnelly C, Deas D. Efficacy of sertraline in the treatment of children and adolescents with major depressive disorder: two randomized controlled trials. JAMA 2003; 290: 1033-41.

43 Wagner KD, Robb AS, Findling RL, Jin J, Gutierrez MM, Heydorn WE. Randomized, placebo-controlled trial of citalopram for the treatment of major depression in children and adolescents. Am J Psychiatry 2004; 161: 1079-83.

44 SmithKline Beecham. A Randomized, Multicenter, 8-Week, Double-blind, Placebo-controlled Flexible-dose Study to Evaluate the Efficacy and Safety of Paroxetine in Children and Adolescents with Major Depressive Disorder (29060/701). GSK. 2001 (www.gsk.com/media/paroxetine/ depression_701_full.pdf) (accessed 16 Dec 2007).

45 Moher D, Cook DJ, Eastwood S, Olkin I, Rennie D, Stroup DF. Improving the quality of reports of meta-analyses of randomized controlled trials: the QUOROM statement. Lancet 1999; 354: 1896-900.

46 Baldessarini RJ, Drug therapy of depression and anxiety disorders. In Goodman \& Gilman's The Pharmacological Basis of Therapeutics, 11th edn (eds LL Brunton, JS Lazo, KL Parker): 429-59. McGraw-Hill, 2005.

47 DerSimonian R, Laird N. Meta-analysis in clinical trials. Control Clin Trials 1986; 7: 177-88.

48 Begg CB, Mazumdar M. Operating characteristics of a rank correlation test for publication bias. Biometrics 1994; 50: 1088-111.

49 Egger M, Davey-Smith G, Schneider M, Minder C. Bias in meta-analysis detected by a simple, graphical test. BMJ 1997; 315: 629-34.

50 Altman DG. Confidence intervals for the number needed to treat. BMJ 1988; 317: 1309-12.

51 Jadad AR, Moore RA, Carroll D, Jenkinson C, Reynolds DJ, Gavaghan DJ, McQuay HJ. Assessing the quality of reports of randomized clinical trials: is blinding necessary? Control Clin Trials 1996; 17: 1-12.

52 Spitzer R, Endicott J, Robins E. Research Diagnostic Criteria (RDC) for a Selected Group of Functional Disorders, 3rd edn. New York State Psychiatric Institute, Biometrics Research Division, 1978.

53 Fawcett J, Barkin RL. Efficacy issues with antidepressants. J Clin Psychiatry 1997; 58 (suppl 6): 32-9.

54 Janicak PG, Davis JM, Preskorn SH, Ayd FJ. Treatment with antidepressants. In Principles and Practice of Psychopharmacology, 3rd edn: 214-325. Lippincott/Williams \& Wilkins, 2001

55 Khan A, Detke M, Khan SR, Mallinckrodt C. Placebo response and antidepressant clinical trial outcome. J Nerv Ment Dis 2003; 191: 211-8.

56 National Institute for Clinical Excellence. Depression in Children and Young People: Identification and Management in Primary, Community and Secondary Care (CG28). NICE, 2005 (http://www.nice.org.uk/nicemedia/pdf/ cg028fullguideline.pdf)

57 Hazell P, O'Connell D, Heathcote D, Robertson J, Henry D. Efficacy of tricyclic drugs in treating child and adolescent depression: meta-analysis. BMJ 1995; 310: 897-901.

58 Hazell $P$, O'Connell D, Heathcote D, Henry D. Tricyclic drugs for depression in children and adolescents. Cochrane Database of Systematic Reviews, issue 2. Update Software, 2002.

59 Jureidini JN, Doecke CJ, Mansfield PR, Haby MM, Menkes DB, Tonkin AL. Efficacy and safety of antidepressants for children and adolescents. $B M J$ 2004; 328: 879-83.

60 Courtney DB. Selective serotonin reuptake inhibitor and venlafaxine use in children and adolescents with major depressive disorder: systematic review of published randomized controlled trials. Can J Psychiatry 2004; 49: 557-63.
61 Whittington CJ, Kendall T, Fonagy P, Cottrell D, Cotgrove A, Boddington E. Selective serotonin reuptake inhibitors in childhood depression: systematic review of published vs. unpublished data. Lancet 2004; 363: 1341-5.

62 Cheung $\mathrm{AH}$, Emslie GJ, Mayes TL. Review of the efficacy and safety of antidepressants in youth depression. J Child Psychol Psychiatry 2005; 46: 735-54.

63 Ryan ND. Treatment of depression in children and adolescents. Lancet 2005; 366: 933-40.

64 Tonkin A, Jureidini J. Wishful thinking: antidepressant drugs in childhood depression. Br J Psychiatry 2005; 187: 304-5.

65 Raz A. Perspectives on the efficacy of antidepressants for child and adolescent depression. PLOS Med 2006; 3: e9.

66 Baldessarini RJ, Faedda GL, Hennen J. Risk of mania with serotonin reuptake inhibitors vs. tricyclic antidepressants in children, adolescents and young adults. Arch Pediatr Adolesc Med 2005; 159: 298-9.

67 Zito JM, Safer DJ, dosReis S, Gardner JF, Boles M, Lynch F. Trends in prescribing of psychotropic medications to preschoolers. JAMA 2000; 283 1025-30.

68 Zito JM, Safer DJ, dosReis S, Gardner JF, Magder L, Soeken K, Boles M, Lynch F, Riddle MA. Psychotropic practice patterns for youth. A 10-year perspective. Arch Pediatr Adolesc Med 2003; 157: 17-25.

69 Delate T, Gelenberg AJ, Simmons VA, Motheral BR. Trends in the use of antidepressants in a national sample of commercially insured paediatric patients, 1998 to 2002. Psychiatr Serv 2004; 55: 387-91.

70 Birmaher B, Ryan ND, Williamson DE, Brent DA, Kaufman J, Dahl RE, Perel J, Nelson B. Childhood and adolescent depression: review of the past ten years. Part I. J Am Acad Child Adolesc Psychiatry 1996; 35: 1427-39.

71 Birmaher B, Ryan ND, Williamson DE, Brent DA, Kaufman J. Childhood and adolescent depression: review of the past 10 years. Part II. J Am Acad Child Adolesc Psychiatry 1996; 35: 1575-83.

72 Harrington R, Whittaker J, Shoebridge $P$, Campbell F. Systematic review of efficacy of cognitive behavior therapies in childhood and adolescent depressive disorder. BMJ 1998; 316: 1559-63.

73 Timimi S. Rethinking childhood depression. BMJ 2004; 329: 1394-7.

74 Biederman J, Faraone SV, Baldessarini RJ, Flood J, Meyer M, Wilens T, Spencer T, Chen L, Weber W. Predicting desipramine levels in children and adolescents: a naturalistic clinical study. J Am Acad Child Adolesc Psychiatry 1997; 36: 384-9.

75 Wilens TE, Cohen L, Biederman J, Abrams A, Neft D, Faird N, Sinha V. Fluoxetine pharmacokinetics in pediatric patients. J Clin Psychopharmacol 2002; 22: 568-75.

76 Wolraich M, Felice ME, Drotar D. Classification of Child and Adolescent Mental Diagnoses in Primary Care: Diagnostic and Statistical Manual for Primary Care, Child and Adolescent Version (DSM-PC). American Academy of Paediatrics, 1996.

77 American Academy of Child and Adolescent Psychiatry. Practice parameters for assessment and treatment of children and adolescents with depressive disorders. J Am Acad Child Adolesc Psychiatry 1998; 37 (suppl 10): 63-83S.

78 Birmaher B, Heydl P. Biological studies in depressed children and adolescents. Int J Neuropsychopharmacol 2001; 4: 149-57.

79 Hrobjartsson A, Gotzsche PC. Is the placebo powerless? Analysis of clinical trials comparing placebo with no treatment. N Engl J Med 2001; 344: 1594-602.

80 Kaufman J, Martin A, King RA, Charney D. Are child-, adolescent-, and adultonset depression one and the same disorder? Biol Psychiatry 2001; 9: 9801001.

81 Martin A, Kaufman J, Charney D. Pharmacotherapy of early-onset depression. Update and new directions. Child Adolesc Psychiatr Clin N Am 2000; 9: $135-57$. 